\title{
Health impact assessment in urban settings
}

\section{Health impact assessment in urban settings}

\section{GUEST EDITORS}

\section{Patrick J. Harris ${ }^{\mathrm{A}, \mathrm{B}}$, Ben F. Harris-Roxas ${ }^{\mathrm{A}}$ and Lynn Kemp ${ }^{\mathrm{A}}$}

${ }^{\mathrm{A} C e n t r e ~ f o r ~ H e a l t h ~ E q u i t y ~ T r a i n i n g, ~ R e s e a r c h ~ a n d ~ E v a l u a t i o n ~(C H E T R E), ~}$

part of the UNSW Research Centre for Primary Health Care and Equity, University of New South Wales

${ }^{\mathrm{B} C o r r e s p o n d i n g ~ a u t h o r . E m a i l: ~ p a t r i c k . h a r r i s @ u n s w . e d u . a u ~}$

Our future is urban and the health impacts of that urbanisation are a concern internationally, nationally and locally within NSW. In 2008, for the first time in history, half the world's population will live in cities. ${ }^{1}$ Growth in urban areas now accounts for the world's entire net population growth. ${ }^{1}$ Australia is already one of the most urbanised countries in the world, with more than three quarters of the population living in urban areas. $^{2}$ The NSW population, over six million, grew by almost $10 \%$ in the past decade. ${ }^{2}$

This issue of the NSW Public Health Bulletin builds on the growing interest in the impact of urbanisation in NSW and focuses on the contribution of health impact assessment (HIA) to sustainable urbanisation. The recently released State Plan: a new direction for $N S W^{3}$ is a timely reminder that health has an active role in the growth and sustainability of the state. The issue shows that our investment in HIA helps the health sector to better consider the health impacts of urbanisation.

The issue builds on the experience of the NSW HIA project over the past five years. Funded by NSW Health and led by the Centre for Health Equity Training Research and Evaluation, the project has developed the capacity of the health system to undertake HIA. The central element of the project has been 'learning by doing, ${ }^{4}$ by undertaking HIAs on policy, program and project proposals. As part of this work, HIAs have been conducted on proposals that directly influence sustainable urban planning; many of these have been described as case studies in this issue.

The NSW Health Impact Assessment Project has formed strong relationships between project participants and colleagues and experts in HIA and in the field of healthy urban planning internationally, nationally and locally within NSW. Many of these colleagues have contributed to this special issue.

Four important messages concerning HIA, health and urbanisation are presented.

The first message reinforces the growing understanding that human well-being and the impacts of urbanisation are closely related. ${ }^{5}$ Local and international authors with experience in HIA, health and urban planning provide similar arguments that:

- health and urban planning are inextricably linked

- further action is required and

- HIA provides real opportunities to progress this action.

The second message is that HIA has been proven to be a mechanism by which health and other sectors involved in sustainable urbanisation can move beyond recognition of common concerns to concrete action. The HIA case studies included in this issue emphasise the value of constructive engagement using the structured and stepwise approach of HIA.

The third message, highlighted by the case studies on the Bungendore, Lower Hunter and Illawarra impact assessments (see Gow et al.; Wells et al.; Furber et al.; this issue), is that HIA should not be limited to urbanisation in big cities. The proportional growth in regional centres and rural towns often dwarfs that occurring in large cities and the impact on existing resources, physical and social infrastructure can be enormous. This situation is not unique to Australia. As noted in the State of the World Population 2007 report 'contrary to general belief, the bulk of urban 
population growth is likely to be in smaller cities and towns, whose capabilities for planning and implementation can be exceedingly weak'. ${ }^{1}$

The fourth message is that successfully responding to the future challenges and opportunities of urbanisation will require a range of actions such as:

- a shift towards healthy public policy increasing the capacity of the health sector to engage intersectorally on urban planning

- understanding the regulatory framework that governs urban planning in NSW

- learning from past lessons concerning advocating for health as part of urbanisation and

- building on the strengths of, and meeting the challenges set by, HIA in NSW to date.

At all levels of the urbanisation debate - global, national and local, it is apparent that health must become actively engaged in order to enhance the sustainability of planning activities. HIA is now established as one tool to facilitate that engagement. This issue of the Bulletin shows that NSW is now in a position, as a world leader on HIA, to support the pivotal future role that urbanisation will play in influencing the health of populations and communities.

\section{References}

1. UNFPA. State of the world population 2007: unleashing the potential of urban growth. United Nations Population Fund. At http://www.unfpa.org/swp/, accessed 13 August 2007.

2. Australian Bureau of Statistics. Year Book Australia 2007. Canberra: Australian Bureau of Statistics, 2007.

3. NSW Government State Plan: a new direction for NSW. Sydney: Premier's Department of Health, 2007.

4. Harris-Roxas B, Simpson S. The NSW Health Impact Assessment Project. N S W Public Health Bull 2005; 16(7-8): 120-3.

5. Capon AG, Dixon JM. Cities, sustainability and health (special edition). N S W Public Health Bull 2007; 18(3-4): 37-72.

\section{Influencing urban environments for health: NSW Health's response}

\section{EDITORIAL}

\section{Sarah V. Thackway ${ }^{\mathrm{A}, \mathrm{C}}$, Andrew J. Milat ${ }^{\mathrm{B}}$ and Elizabeth Develin ${ }^{\mathrm{B}}$}

${ }^{\mathrm{A} C e n t r e ~ f o r ~ E p i d e m i o l o g y ~ a n d ~ R e s e a r c h, ~}$

NSW Department of Health

${ }^{\mathrm{B}}$ Centre for Chronic Disease Prevention and Health Advancement, NSW Department of Health

${ }^{\mathrm{C}}$ Corresponding author. Email:

sarah.thackway@doh.health.nsw.gov.au

The burden of preventable chronic disease is rapidly increasing in New South Wales. ${ }^{1}$ If the potential for preventing chronic diseases is not fully harnessed, it is projected that treatment costs alone for people with diabetes, cardiovascular disease, cancers and musculoskeletal conditions in NSW will rise from approximately $\$ 3.3$ billion in $2000-01$ to $\$ 6.1$ billion by $2020-21 .^{2}$ Addressing this challenge will require a multifactorial approach and there is a growing body of evidence around the links between risk factors apportioned to increasing urbanisation and, more broadly, to the built environment. ${ }^{3-5}$ Creating environments that promote health can play a significant role in reducing rates of death and disability from chronic disease ${ }^{6}$ Compounding the challenge of addressing potentially avoidable chronic diseases is the sustainability of our urban communities, with increasing populations in and around Sydney and coastal NSW in particular. For example, over the next 20 years, population increases of over $50 \%$ are expected in several coastal townships. ${ }^{7}$

The importance of urban planning for health has been identified as a key priority for the NSW Government as described in the: NSW State Plan, ${ }^{8}$ NSW State Health Plan, ${ }^{9}$ Healthy People NSW, ${ }^{10}$ and the NSW Population Health Priority Taskforce. In particular, Healthy People $N S W$ identifies health impact assessment (HIA) as a key tool for affecting change and to strengthen health input into planning decisions. ${ }^{10}$

While in NSW it is local government planners and urban designers who have the ability to directly influence and shape the urban environment, NSW Health is increasing its engagement at both a state and regional level. This issue of 